\title{
Do the origins of primary teeth affect the bond strength of a self-etching adhesive system to dentin?
}

\author{
Camilla Regina Galvão Bengtson ${ }^{(a)}$ \\ Antonio Lucindo Bengtson ${ }^{(b)}$ \\ Nadya Galvão Bengtson (c) \\ Miriam Lacalle Turbino(d)
}

\footnotetext{
(a) PhD Student; (d) PhD, Professor - Department of Restorative Dentistry, School of Dentistry, University of São Paulo, São Paulo, SP, Brazil.

(b) PhD, Professor; (c)MSc, Professor

- Department of Pediatric Dentistry, School of Dentistry, Universidade Metropolitana de Santos, Santos, SP, Brazil.
}

\begin{abstract}
The aim of this in vitro study was to evaluate the tensile bond strength of a self-etching adhesive system to three different dentinal substrates. Primary molar teeth that had been recently exfoliated (RE), with unknown time of exfoliation (UT), and extracted due to prolonged retention (PR) were used for this investigation. Ten primary molar teeth of each group were cut in the middle following the mesio-distal direction, creating a total of twenty specimens per group. The specimens were included in acrylic resin and had a flat dentin surface exposed. The self-etching adhesive system was applied to this surface and a 3-millimeter high cone with diameter of $2 \mathrm{~mm}$ in the adhesion area was constructed using composite resin. The specimens were stored in distilled water at $37^{\circ} \mathrm{C}$ for 24 hours. Fifteen specimens of each substrate were used for the tensile bond test $(\mathrm{n}=15)$ and 5 had the interface analyzed by scanning electron microscopy (SEM). The data was examined by one-way ANOVA and presented no significant differences between groups $(\mathrm{p}=0.5787)$. The mean values obtained for RE, UT and PR were 18.39 $\pm 9.70,19.41 \pm 7.80$, and $23.30 \pm 9.37 \mathrm{MPa}$, respectively. Any dentinal substrates of primary teeth studied are safe for tensile bond strength tests with adhesive systems.
\end{abstract}

Descriptors: Adhesives; Tensile strength; Dental materials; Dentin; Tooth, deciduous.

\section{Introduction}

In vitro tests, such as bond strength measurement, microleakage evaluation and marginal gap calculation are vital screening tests that serve to predict the clinical behavior of new bonding systems. ${ }^{1}$ In any attempt to have more accurate knowledge of the retention capability of bonding systems in the clinical situation, the evaluation of bond strength to hard dental tissue is usually required. , $^{2,3}$

In these laboratory studies, the most suitable substrate is freshly extracted teeth. However, freshly extracted teeth are of limited availability. To meet the target of number of tooth specimens required for an in vitro study, freshly extracted teeth are either typically stored in different solutions or maintained in a dry state during the collection period. Since dentin is a hydrated biological composite structure composed of dentinal tubules, intertubular and peritubular matrices, the manner and time of storage could cause some changes in the microstructure of this substrate. ${ }^{5,6}$
Received for publication on Dec 01, 2009 Accepted for publication on Jun 06, 2010 
Another condition that can cause alterations in dentin substrate is related to age change. Older teeth experience gradual enlargement of peritubular dentin and intratubular mineral deposits, which often result in narrowed or completely occluded tubules. In human primary teeth, root resorption is a physiological process which occurs at the end of that life span. During this phase, some morphological and functional modifications occur to the pulp cells and consequently to the tissues involved in the process. ${ }^{7}$ These modifications may occur because, during this period, dentin and pulp are eliminated by odontoclasts. This condition may suggest that primary teeth in different phases of their vital cycle could have different dentin characteristics. ${ }^{8,9,10}$

The formation of the hybrid layer, by the impregnation of resin ingredients into the demineralized intertubular dentin with subsequent polymerization, is thought to create an adequate bond between resin and dentin. Resin infiltration into the dentinal tubules or resin tags also contribute to bonding. ${ }^{11}$ Thus, bonding mechanism of resin to dentin is dependent on the microstructure of the substrate at the point of bonding. ${ }^{12,13}$

Although the number of studies regarding laboratory tests of the adhesive force of restorative materials (tensile, microtensile, shear, and microshear) in primary teeth has increased, ${ }^{3,14,15,16,17,18}$ only a few of these report the quality of dentin used in the tests. The substrate has an important role in hybrid layer formation. Due to this, substrate standardization of dentin which is used in bond strength is necessary. The purpose of this study was to investigate the influence of storage and exfoliation modes of primary teeth, on the tensile bond strength of a self etch adhesive system to primary dentin. In addition, the adhesive interfaces were analyzed by SEM to observe differences in hybrid layer formation among groups.

\section{Material and Methods}

Thirty sound primary extracted molars were used. The teeth were obtained according to protocols (82/06) approved by the appropriate institutional review board of the School of Dentistry - University of São Paulo, and with the formal consent of the Human Tooth Bank of the School of Dentistry
- University of São Paulo. The teeth were cleaned of debris with pumice paste via a slow-speed handpiece and stored in distilled water until they were used. The teeth were manipulated with individual protection equipment throughout the experiment and only one operator carried out all procedures.

The teeth were divided into three groups according to the exfoliation and storing characteristics. Group 1: recently exfoliated primary molar teeth (RE), obtained and used on the same day of exfoliation. Group 2: primary molar teeth, which were surgically extracted due to prolonged retention (RP), used on the same day of extraction. Group 3: primary molar teeth that were collected with unknown time of exfoliation. This final group of teeth were kept dry for 2 months in an ambient temperature, and then rehydrated in distilled water over a period of 7 days at $4^{\circ} \mathrm{C}$ (UT).

The crowns of the thirty teeth were sectioned parallel to the long axis of the tooth, using a lowspeed diamond saw under water cooling conditions (Buehler Ltd., Lake Bluff, IL, USA). As a result, twenty specimens per group were obtained. Each dental fragment was included in acrylic resin. Enamel surfaces were flattened with 120-, 240-, 400-, and 600- grit silicon carbide papers on a polisher machine (Ecomet 3, Buehler Ltd., Lake Bluff, IL, USA), in order to expose the surface dentin, and standardize the smear layer.

The dentin surfaces were bonded with the selfetching adhesive system, AdheSE (Ivoclar Vivadent AG, Schaan, the Principality of Liechtenstein) according to the manufacturer's instructions. A silicone mold a with cone-shaped perforation measuring $2 \mathrm{~mm}$ in diameter at the base, and $3 \mathrm{~mm}$ in diameter at the top ( $3 \mathrm{~mm}$ in height), adhesion area $=0.0314 \mathrm{~cm}^{2}$, was adjusted on this surface. A composite resin was used to fill the mold. Two increments were applied, each one photoactivated for $40 \mathrm{~s}$ using a light unit with $450 \mathrm{~mW} / \mathrm{cm}^{2}$ (3M Curing Light, 3M ESPE, St. Paul, MN, USA). All specimens were stored in distilled water at $37^{\circ} \mathrm{C}$ for 24 hours.

Following this, fifteen specimens of each substrate $(\mathrm{n}=15)$ were performed in a universal testing machine (Model 4442, Instron Co., Canton, MA, USA), at a crosshead speed of $0.5 \mathrm{~mm} / \mathrm{min}$, for ten- 
sile tests. The failure load divided by the cross-sectional area at the point of fracture for each specimen was used to calculate the tensile bond strength in $\mathrm{MPa}$. After confirmation that the values had normal and homogeneous distribution, the data was statistically analyzed by one-way ANOVA. The SPSS Statistics for the Windows program, version 17.0 (SPSS Inc., Chicago, IL, USA) was utilized and statistical significance was established at $\alpha=0.05$.

After testing, the fracture modes of each specimen were determined by examination in a dissecting microscope at $25 \mathrm{x}$ magnification (Olympus Co., Tokyo, Kanto, Japan). The fracture mode was classified as an adhesive/mixed failure if debonding occurred between the resin and dentin, and as a cohesive failure if it occurred in composite resin or dentin.

The other five specimens of each group were selected for SEM analysis of adhesive interface (model Jeol 2800, Jeol Co., Tokyo, Kanto, Japan). They were partly decalcified in phosphoric acid $(36 \%$ solution, $10 \mathrm{~s})$, deproteinized with sodium hypochlorite ( $2 \%$ solution, $60 \mathrm{~s}$ ), and washed in tap water. Thereafter, the specimens were dehydrated in increasing concentrations of ethanol, immersed $(10 \mathrm{~min})$ in hexamethyldisilazane (HMDS), and completely airdried. These specimens were covered with a goldpalladium layer $(20 \mathrm{~nm})$ for visualization in SEM. Complete extension of the union zone between dentin and resin was analyzed. Electromicrographs (1,500 $\mathrm{x}$ and 3,000 $\mathrm{x}$ magnifications) were obtained for descriptive analysis of the region.

\section{Results}

The one-way ANOVA revealed no statistically

Table 1 - Mean bond strength (MPa) and standard deviation of the adhesive system to the different dentin substrates ( $\mathrm{n}=15)$.

\begin{tabular}{c|c|c}
\hline Groups & Bond Strength $(\mathrm{MPa})$ & ANOVA \\
\hline Recently exfoliated & $18.39 \pm 9.70$ & $\mathrm{~A}$ \\
\hline Prolonged retention & $23.30 \pm 9.37$ & $\mathrm{~A}$ \\
\hline Unknown time & $19.41 \pm 7.80$ & $\mathrm{~A}$ \\
\hline
\end{tabular}

Mean values followed by the same letter were not significantly different $(p>0.05)$. significant difference in the tensile bond strength to dentin among the three groups $(\mathrm{p}=0.5787$ and $\mathrm{f}=0.8895$ ). The mean tensile bond strength values and standard deviations for each experimental condition are shown in Table 1.

The failure modes of tested specimens are represented in Graph 1. Adhesive/mixed failure was predominant in all groups, independent of the exfoliation mode or storing conditions.

The SEM observation of adhesive interfaces indicated that the hybrid layer was not uniform in complete extension of the union zone, with values in the range of $1-3 \mu \mathrm{m}$. In addition, a high number of resinous tags, homogeneously distributed, were observed in this area. Differences between the three groups were not detected (Figure 1).

\section{Discussion}

The microstructure of dentin at the site of bonding is extremely important in the formation of the bonding mechanism of resin to dentin. ${ }^{19}$ Since dentin is a dynamic substrate, ${ }^{20}$ this research proposed analyzing the quality of bonding in three different situations. Studies have shown that the tensile bond strength of adhesive systems can be influenced by dentin age and time of storage in permanent teeth. ${ }^{21,22}$

Data from literature demonstrates that adhesion force of composite resin systems, as applied to primary dentin, ranges from 5.53 to $70.1 \mathrm{MPa} .^{3,23}$ This

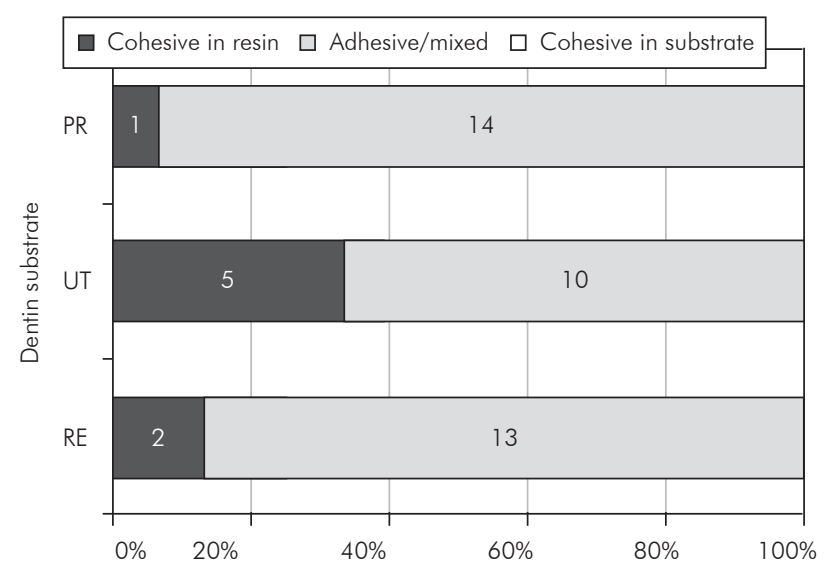

Graph 1 - The failure modes of tested specimens per substrate. 

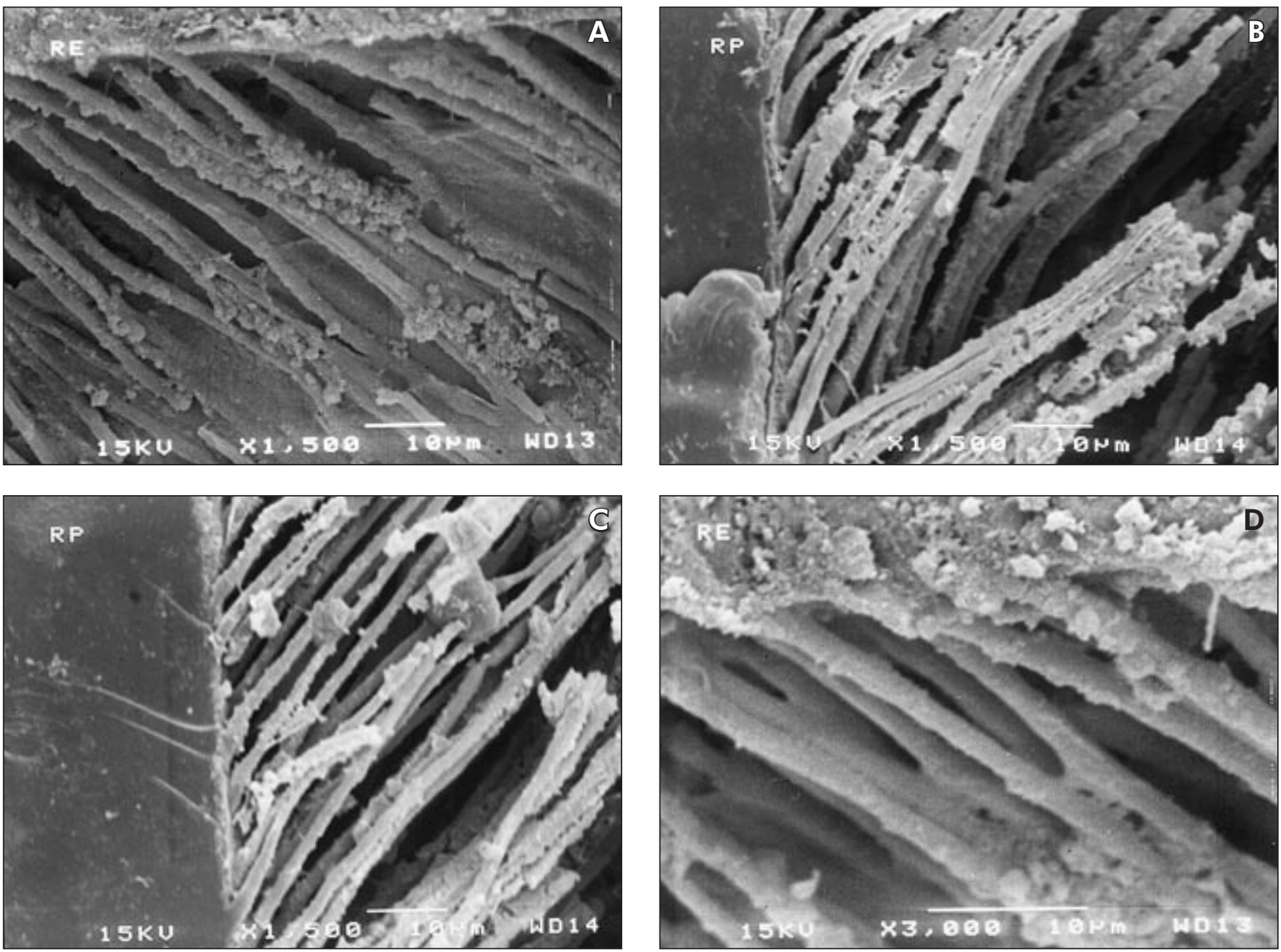

Figure 1 - Hybrid layer and tags in (A) recently exfoliated dentin substrate, (B) dentin substrate with unknown exfoliation time, and $(\mathbf{C})$ dentin substrate with prolonged retention (1,500 x magnification); (D) higher tag magnification (3,000 x).

wide variation is explained by differences between the methods employed, as well as factors related to the tooth and material used. In a small number of such studies, the origin of the primary teeth was reported. Due to the lack of studies in the literature concerning different conditions with primary dentin, results from studies with permanent teeth were taken as reference, and our results are in agreement with them.

Considering time and storage conditions of the teeth after the extraction, some questions concern how changes within dentin after extraction may influence adhesion in vitro dentin bond studies. Titley et al. ${ }^{5}$ stated that post-mortem changes could occur in dentin, with the potential to affect the outcome of bond strength tests. However, in another study that compares shear bond strength of dentin to restorative material, no significant differences were observed between the group stored in distilled water for eight days and the other stored for six months. ${ }^{22}$ Research about utilization of dry and rehydrated tooth in tensile bond strength showed that the differences between the dentin substrates do not appear to be critical for the tensile bond strength test, observing that the dentinal substrates showed similar performances with three adhesive systems. ${ }^{24}$ In this study, these observations may be illustrated by electromicrographs of hybrid layers formed in the groups of recently-extracted teeth and those of unknown time of extraction, which present long resinous extensions and similar thickness (Figure 1).

A reduction in the tensile bond strength values 
could be expected for the group of teeth with prolonged retention, because they present substrate alterations, such as sclerotic dentin and dentinal tubules with smaller diameter, density, and permeability due to the aging process and enlarged vital cycle. ${ }^{9,10}$ Since this physiological process occurs at different speeds and in different ways in teeth with prolonged retention, some differences in dentin microstructure, when compared to exfoliated primary teeth, are expected to be found.

Some studies that used self-etching adhesive systems such as the ones employed in this study observed smaller adhesion, formation of hybrid layer, and tags in sclerotic dentin. ${ }^{25,26}$ However, the selfconditioning adhesive utilized was able to efficiently improve the mineralized parts in that surface, ${ }^{27}$ forming a hybrid layer similar to that observed in the group of recently-extracted teeth (Figure 1), with similar tensile bond strength results (Table 1).

In this study, a group formed by rehydrated primary molar teeth, with unknown time of exfoliation, was tested. Although this group can cause some doubt about the variability of what is being analyzed, that is, storage or exfoliation mode, it did not demonstrate any statistical difference compared to the other groups. Additionally, because of the difficulty in the collection of specimens, most studies on bond strength using primary teeth are formed by teeth with unknown time of exfoliation and storing, representative of this group.

There is a tendency for large bonded surface areas to produce cohesive failures in dentin at relatively low bond strength. ${ }^{17}$ In this study, primary molar teeth were used, which have a small flat dentin surface area. The manipulation of thin specimens in conventional microtensile bond strength tests is extremely critical. A smaller diameter matrix $(2.0 \mathrm{~mm}$ diameter hole) for tensile bond strength was used to prepare the specimens with reduced bonding area $\left(0.0314 \mathrm{~cm}^{2}\right) .{ }^{28}$ The tensile bond strength test applied with a reduced bonding area permitted high bond values and eliminated the occurrence of cohesive failures (Graph 1) in dentin without difficulties in specimen manipulation.

Scanning electron microscopy (SEM) is a meth- od that allows efficient evaluation of adhesive interfaces. In addition, it permits careful observation and analysis of structural characteristics (thickness, porosity, length, penetration and interaction) of the dental adhesive system set, namely composite resin, adhesive system, hybrid layer, tags, gaps, and dentin tubules. . $^{1,2,3,4}$

Presence of a small number of structural defects (microcracks and gaps) was observed in electromicrographs of all groups studied. However, in the majority of occasions such defects were located in peripheral parts of the specimens, suggesting that they could have been inserted during preparation. Soares et al. ${ }^{3}$ and Uekusa et al..$^{4}$ studied adhesion of self-conditioning systems in primary dentin by the microtensile bond strength test and SEM, and observed that the hybrid layer formed had optimal, uniform, and continuous adaptation. In our findings with the self-etching adhesive system, ADheSe, the hybrid layer observed in the three substrates were not uniform, with differences in thickness being detected throughout the analyzed areas. However, they are well adapted, continuous, with long resinous tags, and distributed homogeneously, resulting in a good-quality adhesive layer (Figure 1). It is known that the variations observed in the thickness of the hybrid layer of primary teeth has not been associated with adhesion values. ${ }^{29}$

Many factors can interfere in the bonding quality of resin to dentin substrate. The results of this study can contribute to the reduction in preoccupation with dentin substrates in future studies using deciduous tooth dentin for bonding tests with self etch adhesive systems.

\section{Conclusion}

Any of the three dentin substrates of primary teeth (recently exfoliated, with unknown time of exfoliation or extracted due to prolonged retention) can safely be used in tensile bond strength tests with resinous systems in future studies. The quality of the hybrid layer formed with the adhesive ADheSe and the adhesion values show that this adhesive is effective for utilization in primary dentin. 


\section{References}

1. Puppin-Rontani RM, De Góes MF, Voelske CE, García-Godoy F. Clinical performance and SEM evaluation of direct composite restorations in primary molars. Am J Dent. 2006 Oct;19(5):255-61.

2. Nör JE, Feigal RJ, Dennison JB, Edwards CA. Dentin bonding: SEM comparison of the resin-dentin interface in primary and permanent teeth. J Dent Res. 1996 Jun;75(6):1396-403.

3. Soares FZ, Rocha R de O, Raggio DP, Sadek FT, Cardoso PE. Microtensile bond strength of different adhesive systems to primary and permanent dentin. Pediatr Dent. 2005 NovDec;27(6):457-62.

4. Uekusa S, Yamaguchi K, Miyazaki M, Tsubota K, Kurokawa $\mathrm{H}$, Hosoya Y. Bonding efficacy of single-step self-etch systems to sound primary and permanent tooth dentin. Oper Dent. 2006 Sep-Oct;31(5):569-76.

5. Titley KC, Chernecky R, Rossouw PE, Kulkarni GV. The effect of various storage methods and media on shear-bond strengths of dental composite resin to bovine dentine. Arch Oral Biol. 1998 Apr;43(4):305-11

6. Susin AH, Vasconcellos WA, Saad JRC, Oliveira-Junior OB. Tensile bond strength of self-etching versus total-etching adhesive systems under different dentinal substrate conditions. Braz Oral Res. 2007 Jan-Mar;21(1):81-6.

7. Rodrigues LV, Vasconcelos AC, Campos PA, Brant JMC. Apoptosis in pulp elimination during physiological root resorption in human primary teeth. Braz Dent J. 2009;20(3):17985.

8. Watanabe LG, Marshall Jr GW, Marshall SJ. Dentin shear strength: effects of tubule orientation and intratooth location. Dent Mater. 1996 Mar;12(2):109-15.

9. Klinge RF. Further observations on tertiary dentin in human primary teeth. Adv Dent Res. 2001 Aug;15:76-9.

10. Nalla RK, Porter AE, Daraio C, Minor AM, Radmilovic V, Stach EA, et al. Ultrastructural examination of dentin using focused ion-beam cross-sectioning and transmission electron microscopy. Micron. 2005 Oct-Dec;36(7-8):672-80.

11. Nakabayashi N, Ashizawa M, Nakamura M. Identification of a resin-dentin hybrid layer in vital human dentin created in vivo: durable bonding to vital dentin. Quintessence Int. 1992 Feb;23(2):135-41.

12. Rocha PI, Borges AB, Rodrigues JR, Arrais CAG, Giannini M. Effect of dentinal surface preparation on bond strength of self-etching adhesive systems. Braz Oral Res. 2006 JanMar;20(1):52-8.

13. Tay FR, Sano H, Carvalho RM, Pashley EL, Pashley DH. An ultrastructural study of the influence of acidity of self-etching primers and smear layer thickness on bonding to intact dentin. 2000 Summer;2(2):83-98.

14. Araújo FB, García-Godoy F, Issáo M. A comparison of three resin bonding agents to primary tooth dentin. Pediatr Dent. 1997 May-Jun;19(4):253-7.
15. Bolaños-Carmona V, González-López S, Briones-Luján T, De Haro-Muñoz C, de la Macorra JC. Effects of etching time of primary dentin on interface morphology and microtensile bond strength. Dent Mater. 2006 Dec;22(12):1121-9.

16. Cehreli ZC, Akça T. Effect of dentinal tubule orientation on the microtensile bond strength to primary dentin. J Dent Child (Chic). 2003 May-Aug;70(2):139-44.

17. Pashley DH, Sano H, Ciucchi B, Yoshiyama M, Carvalho RM. Adhesion testing of dentin bonding agents: a review. Dent Mat. 1995 Mar;11(2):117-25.

18. Santana FR, Pereira JC, Pereira CA, Fernandes-Neto AJ, Soares CJ. Influence of method and period of storage on the microtensile bond strength of indirect composite resin restorations to dentine. Braz Oral Res. 2008 Oct-Dec;22(4):352-7.

19. Marshall GW, Marshall SJ, Kinney JH, Balooch M. The dentin substrate: structure and properties related to bonding. J Dent. 1997 Nov;25(6):441-58.

20. Pashley DH, Carvalho RM. Dentine permeability and dentine adhesion. J Dent. 1997 Sep;25(5):355-72

21. Giannini M, Chaves P, Oliveira MT. Effect of tooth age on bond strength to dentin. J Appl Oral Sci. 2003 OctDec;11(4):342-7.

22. Goodis HE, Marshall GW Jr, White JM, Gee L, Hornberger B, Marshall SJ. Storage effects on dentin permeability and shear bond strengths. Dent Mater. 1993 Mar;9(2):79-84.

23. Salama FS. Gluma bond strength to the dentin of primary molars. J Clin Pediatr Dent. 1994 Fall;19(1):35-40.

24. Muench A, Silva EM, Ballester RI. Influence of different dentinal substrates on the tensile bond strength of three adhesive systems. J Adhes Dent. 2000 Autumn;2(3):209-12.

25. Kwong SM, Tay FR, Yip HK, Kei LH, Pashley DH. An ultrastructural study of the application of dentine adhesives to acidconditioned sclerotic dentine. J Dent. 2000 Sep;28(7):51528.

26. Tay FR, Kwong SM, Itthagarun A, King NM, Yip HK, Moulding $\mathrm{KM}$, et al. Bonding of a self-etching primer to non-carious cervical sclerotic dentin: interfacial ultrastructure and microtensile bond strength evaluation. J Adhes Dent. 2000 Spring;2(1):9-28.

27. Ferrari M, Mannocci F, Vichi A, Davidson CL. Effect of two etching times on the sealing ability of Clearfil Liner Bond 2 in class V restorations. Am J Dent. 1997 Apr;10(2):66-70.

28. Stalin A, Varma BR, Jayanthi. Comparative evaluation of tensile-bond strength, fracture mode and microleakage of fifth, and sixth generation adhesive systems in primary dentition. J Indian Soc Pedod Prev Dent. 2005 Jun;23(2):83-8.

29. Nakornchai S, Harnirattisai C, Surarit R, Thiradilok S. Microtensile bond strength of a total-etching versus self-etching adhesive to caries-affected and intact dentin in primary teeth. J Am Dent Assoc. 2005 Apr;136(4):477-83. 